the results of three experiments in three pigs the half-life of GOT determined by measuring enzyme activity (after deduction of serum enzyme activity before the injection) was $18 \mathrm{~h}$, while radioactivity measurements gave a result of $16 \mathrm{~h}$. For GPT the results were $51 \mathrm{~h}$ and $57 \mathrm{~h}$ respectively. Fleisher et al. ${ }^{7}$ found approximately the same halflives in dogs using determination of enzyme activity only. The percentage immune inhibition of enzyme activity of both GOT and GPT was also unaltered during the course of experiment (Figs. 1 and 2).

We have determined the Michaelis constants of pig GOT 10.5 and $30 \mathrm{~h}$, and of pig GPT 7,30 and $78 \mathrm{~h}$, after the intravenous injection in pig serum according to Lineweaver-Burk. $K_{m}$ values for GPT (0.1 M, and $10 \mathrm{mM}$ using $\alpha$-ketoglutaric acid and L-aspartate) were unchanged. $K_{m}$ values for GPT $(0.09 \mathrm{mM}$, and $17.5 \mathrm{mM}$ using $\alpha$ ketoglutaric acid and L-alanine) were also identical during the time of the experiment.

These experiments have shown that these clinically important enzymes do not undergo measurable inactivation while present in the bloodstream. The immunological characteristics and the kinetic properties of these enzymes also remained unaltered under the experimental conditions.

\title{
Medizinische Univ.-Poliklinik,
}

SADEgh MassarRat Marburg/Lahn, Germany.

${ }^{1}$ Schapira, F., Dreyfus, J. C., and Schapira, G., Extrait Rev. Frane. Etud. Clin. Biol., 7,829 (1962),

${ }^{2}$ Lang, N., and Massarrat, S., Verh. Deutsch. Ges. inn. Med., 68, 275 (1962).

${ }^{3}$ Massarrat, S., and Lang, N., Trans. Seventh Intern. Congr. Intern. Med., 1, 508 (1962) (Georg Thieme Verlag, Stuttgart, 1963).

4 Report of the Commission on Enzymes, I.U.B. Symposium Series, 20 (Pergamon Press, London, 1961).

${ }^{5}$ Massarrat, S., and Lang, L., Klin. Wschr. (in the press).

${ }^{6}$ Francis, G. E., Mulligan, W., and Wormall, A., Nature, 167, 748 (1951).

'Fleisher, G. A., and Wakim, K. G., J. Lab. Clin. Med., 61, 76 (1963).

\section{Metabolism of Oestrogenic Isoflavones in Sheep}

BIOCHanin $A(\mathrm{I})$, genistein (II) and formononetin (III) have been shown to act as oestrogens in mice, rats and guinea-pigs, and are considered to be responsible for the depression of fertility noted in sheep grazing subterranean clover ${ }^{1}$. An examination has now been made of the urinary metabolites produced when these isoflavones are administered to sheep. Nilsson ${ }^{2}$ reported that biochanin $A$, injected intraperitoneally into rats, was largely excreted in the faeces as biochanin $A$ and genistein or their conjugates. In our experiments with sheep, only trace amounts of free or conjugated isoflavones were found in the faeces.

$\mathrm{HO}$

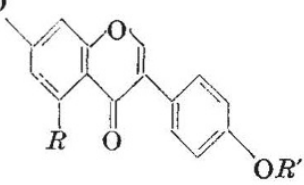

I, $\quad R=\mathrm{OH}, R^{\prime}=\mathrm{Me}$

II, $R=\mathrm{OH}, R^{\prime}=\mathrm{H}$

III, $R=\mathrm{H}, R^{\prime}=\mathrm{Me}$

IV, $R=R^{\prime}=\mathrm{H}$

Biochanin $A$ and genistein, given intraruminally to ovariectomized ewes, were extensively degraded and $p$-ethyl phenol was isolated as the major metabolite. Both $p$-ethyl phenol and the small amounts of undegraded biochanin $A$ and genistein were excreted in conjugate form, and were extracted after acid hydrolysis of the urine. In untreated ewes and in ewes treated with formononetin, $p$-ethyl phenol was only a minor component of the urine phenols ( $<5$ per cent), which consisted mainly of $p$-cresol (up to 65 per cent of the total phenols). The amount of $p$-ethyl phenol in the urines was roughly pro- portional to the dose of biochanin $A$ or genistein, and at high dose levels ( $5 \mathrm{~g}$ per day for 4 days) the yield of $p$-ethyl phenol amounted to 60-65 per cent of the total phenols, and was equivalent to $60-80$ per cent of the ingested isoflavone. Urine from animals given intraruminal doses of biochanin $A$ ( $5 \mathrm{~g}$ per day) yielded more biochanin $A$. (about $130 \mathrm{mg} /$ day) than genistein (trace only), suggesting that demethylation is necessary before metabolism to $p$-ethyl phenol occurs. Biochanin $A$ or genistein given intramusculariy $(0.25 \mathrm{~g} /$ day for 4 days $)$ did not increase the $p$-ethyl phenol content of the urine.

Formononetin given intraruminally did not alter significantly the composition of the simple urine phenols; the metabolites identified were daidzein (IV) and the isoflavan, equol (V), with a little unchanged formononetin. The mode of administration is important, for formononetin injected intramuscularly appeared to be largely excreted unchanged. However, the proportion excreted is not known with certainty because of incomplete absorption of formononetin into the bloodstream: as much as 80 per cent of the injected formononetin was recovered by extracting the tissue surrounding the injection sites. It has been claimed ${ }^{3}$ that genistein is partially converted into equol in hens, but this apparently does not apply to sheep. In our experiments equol could not be detected in the urine of sheep given genistein or biochanin $A$ either intraruminally or intramuscularly.

Nilsson $^{4,5}$ has demonstrated that the major reaction occurring in rumen liquor incubations of biochanin $A$ and formononetin is demethylation to genistein and daidzein respectively. We have obtained similar results and have found no evidence of more extensive degradation of isoflavones in rumen liquor in vitro.

The oestrogenic activity of the phenols recovered from sheep urine after intraruminal or intramuscular administration of isoflavones was determined by bioassay in mice. The activity was low, and of the order expected from the known amounts of isoflavones present. It has been sug. gested that the isoflavones are pro-oestrogens ${ }^{6}$, but if in fact they are converted into more active oestrogens in the animal these are either not excreted or are decomposed during the acid hydrolysis of the urine. These findings are being checked with isoflavones labelled with carbon-14, and a more detailed account of this work will be published later.

$$
\begin{aligned}
& \text { T. J. Batterham } \\
& \text { N. K. Hart } \\
& \text { J. A. Lamberton }
\end{aligned}
$$

Division of Organic Chemistry,

\section{C.S.I.R.O. Chemical Research Laboratories,} Box 4331, G.P.O., Melbourne.

A. W. H. BRADEN

Ian Clunies Ross Animal Research Laboratory,

C.S.I.R.O. Division of Animal Physiology, P.O. Box 144,

Parramatta, New South Wales.

${ }^{1}$ Moule, G. R., Braden, A. W. H., and Lamond, D. R., Anim. Breed. Abst. (Commonwealth Agricultural Bureaux), 31, 139 (1963).

${ }^{2}$ Nilsson, A., Acta Chemica Scand., 16, 31 (1962).

${ }^{3}$ Cayen, M. N., Carter, A. L., and Common, R. H., Biochim. Biophys. Acto, 86, 56 (1964).

4 Nilsson, A., Arkiv Kemi, 17, 305 (1961).

5 Nilsson, A., Arkiv Kemi, 19, 549 (1962).

- Biggers, J. D., and Curnow, D. H., Biochem. J., 58, 278 (1954).

\section{Distribution of Selenium in Tissues of Normal and Dystrophic Chickens}

IN our earlier work on dystrophic chickens we determined the selenium content of fresh eggs from normal and dystrophic birds ${ }^{1}$. We found about $11 \mu \mathrm{g}$ of selenium per egg and no difference between the normal and dystrophic state.

We then proceeded to investigate whether all the selenium in the egg is incorporated into the embryo 